\title{
Variation of GPS- Tec Measurements of the Year 2014: A Comparative Study with IRI - 2016 Model
}

\author{
B. D. Ghimire, N. P. Chapagain, V. Basnet, \\ K. Bhatta and B. Khadka
}

Journal of Nepal Physical Society

Volume 6, Issue 1, June 2020

ISSN: 2392-473X (Print), 2738-9537 (Online)

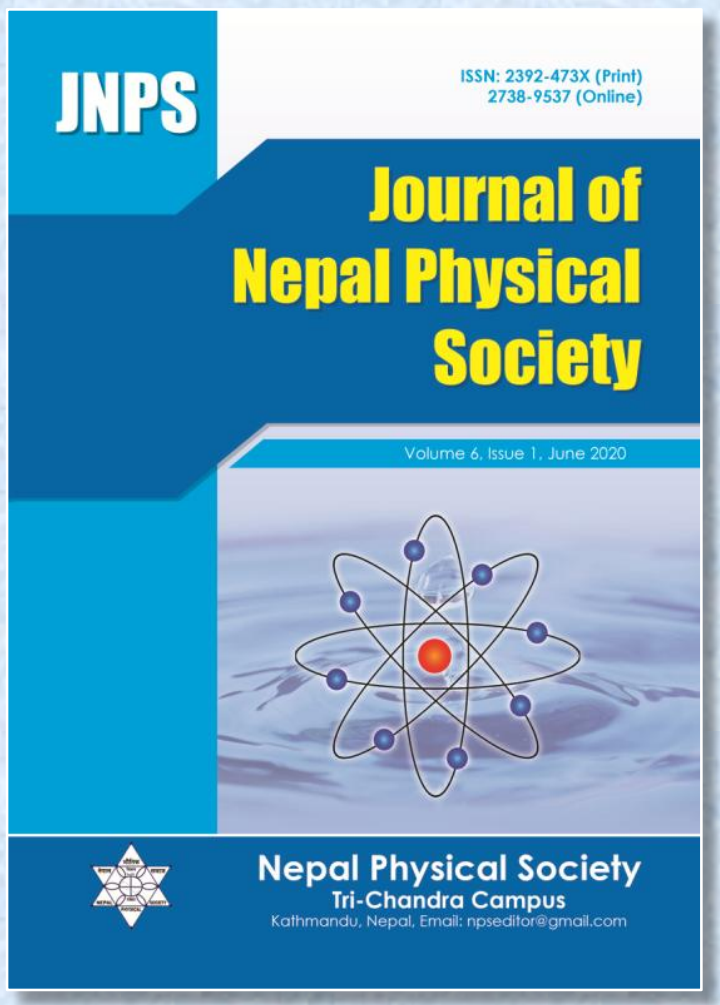

JNPS, 6 (1), 90-96 (2020)

DOI: http://doi.org/10.3126/jnphyssoc.v6i1.30555

Published by:

Nepal Physical Society

P.O. Box: 2934

Tri-Chandra Campus

Kathmandu, Nepal

Email: npseditor@gmail.com 


\title{
Variation of GPS- Tec Measurements of the Year 2014: A Comparative Study with IRI - 2016 Model
}

\author{
B. D. Ghimire ${ }^{1,2,5, *}$, N. P. Chapagain ${ }^{3}$, V. Basnet ${ }^{2,5}$, K. Bhatta $^{4,5}$ and B. Khadka ${ }^{2,5}$ \\ ${ }^{1}$ Institute of Science and Technology, Department of Physics, Tribhuvan University, Nepal \\ ${ }^{2}$ St.Xavier's College, Maitighar, Kathmandu, Nepal \\ ${ }^{3}$ Amrit Campus, Tribuvan University, Lainchaur, Nepal \\ ${ }^{4}$ National Academy of Science and Technology, Khumaltar \\ ${ }^{5}$ Nepalese Center for Research in Physical Sciences, Kathmandu, Nepal \\ *Corresponding Email: basu.ghimire99@gmail.com
}

Received: 7 Apr., 2020; Revised: 25 May, 2020; Accepted: 25 Jun., 2020

\begin{abstract}
Total Electron Content (TEC) measured from Global Positioning System (GPS) receivers at latitude of $29.17^{\circ} \mathrm{N}$ and longitude of $80.62^{\circ} \mathrm{E}$ in Bardiya and TEC derived from IRI- 2016 model is compared for the year 2014, which is geo- magnetically active year. To find out the reliability of IRI-2016 model, comparative study of GPS- TEC and IRI- TEC is very helpful for the study of TEC variations. In this work diurnal, day to day, month to month and seasonal variations of GPS- TEC and IRI- TEC are analyzed. The comparative study shows that the highest value of VTEC (53 TECU) is found on the day of 61 and over estimation of IRI-TEC over GPS TEC were found from day 151 to day 258. Similarly, months of March and December are the highest and lowest values of VTEC obtained respectively. For monthly variation, IRI-TEC is followed by the pattern of variation with GPS- TEC, where peak value is found to be around 0800 UT to 1100 UT (0145 LT to $0445 \mathrm{LT})$. The higher values of both GPS- TEC and IRI TEC have been found in spring season, while the lower values are in winter season in case of IRI TEC and partially in summer (before 1000 UT) and winter (after 10UT) in case of GPS TEC. The maximum difference between the value of IRI modeled TEC and GPS TEC has been found to be around 15 TECU, whereas the minimum value is almost around 1 TECU. The correlation between IRI- 2016 modeled TEC and GPS- TEC has been found to be positive (0.57) showing good matching on variations of GPS TEC and IRI-model results.
\end{abstract}

Keywords: GPS, GPS-TEC, IRI-TEC, VTEC.

\section{INTRODUCTION}

Ionosphere is the upper part of the atmosphere where most of the solar and magnetic activities take place. Free electrons and ionized molecules affect the propagation of electromagnetic wave which are found in ionospheric layers [1,2].Total Electron Content (TEC) is an important descriptive parameter of the ionosphere which can obtained from the propagation delay. It is the total number of electrons present along any path between the receiver and the satellite, with units of electrons per square meter, where $10^{16}$ electrons per $\mathrm{m}^{2}=1$ TEC unit (TECU) [3]. TEC is dependent on time, latitude, longitude, solar and magnetic activities and local atmosphere. So, the changes in the value of TEC is well dependent on Equatorial Anomaly (EIA) in case of low- latitude region and other dynamic processes such as the equatorial spread-F (ESF) irregularities because of intense solar radiation on this region[4].

The influences of ionosphere is going to important day by day so the GPS-TEC data are useful to study which increases the availability of TEC data [5]. Over the last few years, ionospheric TEC was studied using GPS technique by several authors $[4,6,7,8]$. GPS provides the data with better accuracy in time and space and is used for ground based ionospheric studies [8,9]. The ionosphere exhibits different features like diurnal, seasonal and spatial variability[10]. So, different studied have 
been performed on variation with local time, season and solar activities studied $[7,9,11,12]$.

Empirical models can provide reliable simulation data for effective ionospheric study and forecasting [13]. For proper study, different empirical models have been made in past few decades $[14,15,16]$. The IRI (International Reference Ionosphere) model is considered to be popular one. The latest developed model is IRI- 2016. The IRI is a joint undertaking by the Committee on Space Research (COSPAR) and the International Union of Radio Science (URSI) with the goal of developing and improving an international standard for the parameters in Earth's ionosphere [15]. The accuracy of the IRI in a specific region and time period depends on the availability of reliable data for that specific region and time [17]. One important role of IRI is as a background ionosphere model for validating the reliability and accuracy of a particular approach for deducing ionospheric parameters from geodetic measurements [18. In this study, the comparison between GPS- TEC and IRI2016 model have been carried out.

\section{DATA AND METHOD}

\subsection{GPS- TEC}

GPS measurements based on dual frequency signals $\mathrm{f}_{1}(1575.42 \mathrm{MHz})$ and $\mathrm{f}_{2}(1227.60 \mathrm{MHz})$ have been used to obtain the vertical total electron content (VTEC) data. The TEC data is obtained from GPS measurements, which is made available by UNAVCO for the year 2014 at latitude of $29.17^{\circ} \mathrm{N}$ and longitude of $80.62^{\circ} \mathrm{E}$. The TEC data is available in the form of RINEX (Receiver Independent Exchange Format). The RINEX files are processed into ASCII files. At first, data of every $15 \mathrm{sec}$ is available which is processed into hourly data by using python code. The Slant Total Electron Content (STEC) is received by receiver which is later processed into Vertical Total Electron Content (VTEC) according to the relation [8]:

$\mathrm{VTEC}=\left(\mathrm{STEC}-\left[\mathrm{b}_{\mathrm{R}}+\mathrm{b}_{\mathrm{S}}\right]\right) / \mathrm{S}(\mathrm{E})$

where $b_{R}$ and $b_{S}$ are receivers and satellite biases, respectively, $\mathrm{E}$ is the elevation angle of the satellite in degrees, $S(E)$ is the obliquity factor with zenith angle ' $\mathrm{Z}$ ' at the ionospheric pierce point (IPP) is where the GPS signals travels through the maximum electron density lare of the ionosphere basically mean IPP for the density profile is 350$450 \mathrm{~km}$ from the surface of the earth. The obliquity factor $\mathrm{S}(\mathrm{E})$ (or mapping function) is defined as
$S(E)=\frac{1}{\cos (Z)}=\left\{1-\left(R_{E} * \frac{\cos (E)}{R_{E}+h_{S}}\right) \wedge 2\right\} \wedge-0.5$

where $R_{E}$, is the mean radius of the earth in $\mathrm{km} ; h_{s}$, the ionosphere (effective) height above the earth's surface. Rama Rao et al [19] observed that the IPP altitude of greater than $350 \mathrm{~km}$ is valid for the satellite elevation angle greater than $50^{\circ}$.

\subsection{TEC from IRI- 2016 model}

IRI model is developed to avoid the uncertainties of the evolving theoretical understanding of ionospheric processes and coupling to the regimes below and above [5]. IRI models provide sets of data for particular latitude, longitude, date and time and its new version are developed continuously by upgrading previous version and the latest version is IRI- 2016, which covers the limitations of IRI2012 model in total number of stations data used to sampling. This model provides three different options for the topside electron density options (Nequick, IRI-2001, and IRI-01-Corr) and three options for bottom side thicknesses (Bil-2000, Gul1987, and ABT-2009), which are the most important parameters controlling TEC and the electron density profile [8]. TEC from IRI- 2016 model have been taken from its homepage https://ccmc.gsfc.nasa.gov/modelweb/models/iri201 6_vitmo.php.

It is the international standard empirical model for the terrestrial ionosphere since 1999. For a specified geographic location, time, and date, IRI provides average monthly values for electron density, electron temperature and ion temperature, and the molecular composition of the ions in the range of altitudes from $50 \mathrm{~km}$ to $2000 \mathrm{~km}$ [13].

\section{RESULTS AND DISCUSSIONS}

\subsection{Day to Day Variability}

Figure (1) shows the day to day variability of VTEC obtained from GPS and TEC obtained from IRI. There is similar pattern of variations of TEC shown by GPS- TEC and IRI model. The highest value of GPS- TEC has been found to be 53.02 TECU on day of year (DOY) 61 and the highest value of TEC from IRI- 2016 model has been found to be 35.95 TECU on DOY 103. From DOY 151 to 258, monsoon occurs in Nepal so decreasing valu of VTEC is explained. During monsoon, solar radiation is low which affects the value of GPSTEC. TEC from IRI has been taken under quite 
condition which does not include solar and magnetic activities for the prediction of TEC.

IRI- model overestimates the value of TEC from DOY 1 to 50 , underestimates from DOY 51 to 80 , and again overestimates from DOY 81 to 365 with several underestimations between these days. In Bilitza et al. [2017] [15], authours predicated clamitological variation of GPS-TEC and found dependence of TEC variation on local climate. Our results also show the similar pattern of varations TEC.

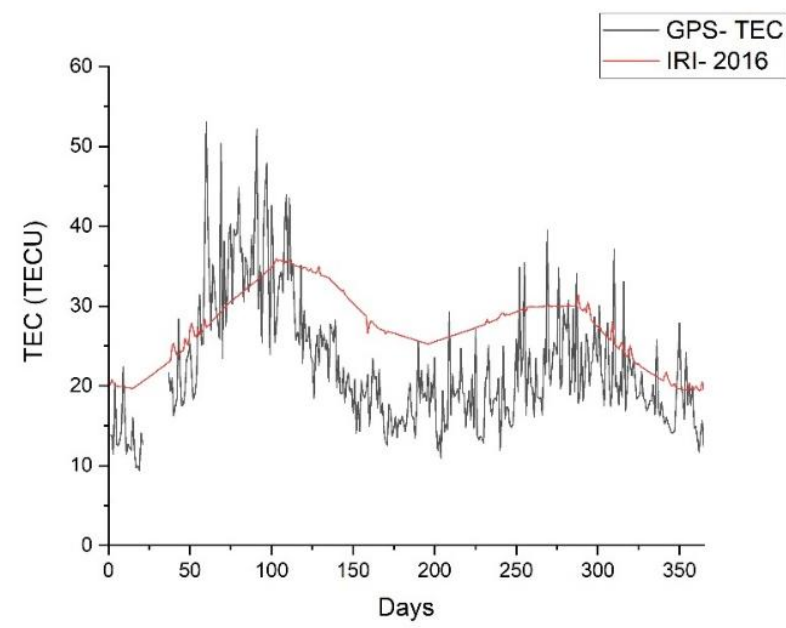

Fig. 1: Day to Day Variability of GPS-TEC and IRI- TEC

Figure (2) shows the correlation of value of TEC obtained from GPS and IRI model of the year 2014. There is positive correlation between modeled TEC and GPS- TEC with value of 0.578 . It shows that the estimation of TEC from IRI- model and with GPS- TEC is correlated.

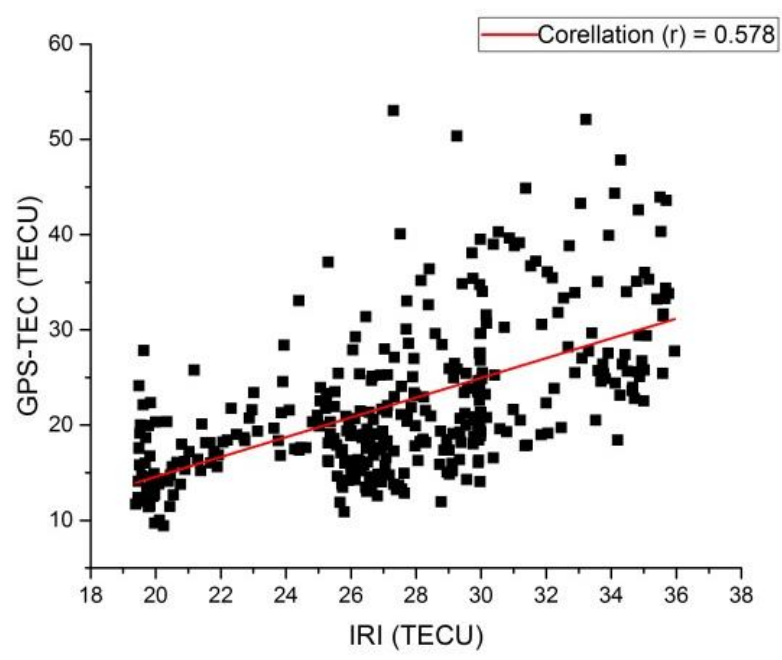

Fig. 2: Correlation between GPS- TEC and IRI-TEC

\subsection{Diurnal Variation}

Figure (3) shows the diurnal variations of average VTEC obtained from GPS on every month. It shows the typical diurnal variation with pre- dawn minimum with gradual increment, peak value at noon and gradual decrement in afternoon to minimum value after sunset. Here the difference of Nepal slandered time (LT) with the universal time is LT $=\mathrm{UT}+5: 45$. The peak value of GPS- TEC has been observed around 0800 UT to 1100 UT (01:45 to $04: 45 \mathrm{LT})$ it may be due to intense radiation then exact noon time. The highest value of TEC has been obtained on March and April as VTEC depends upon local time, seasons etc. In this month, there is high solar activity which increases the solar flux and the rate of photoionization this may be the one of the important factors causing increase in TEC.

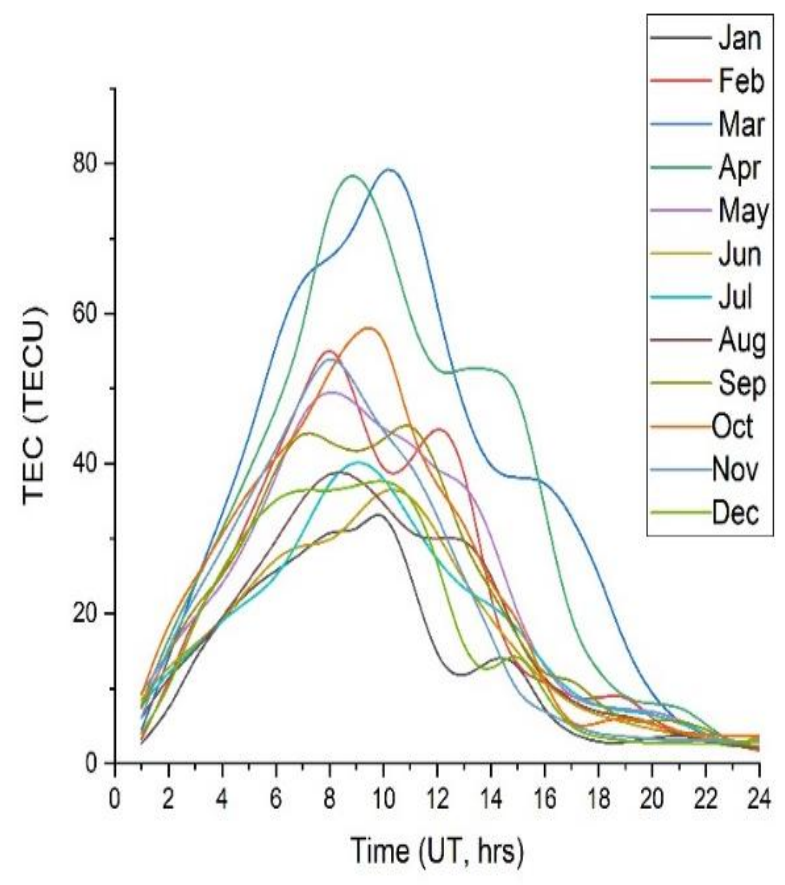

Fig. 3: Diurnal Variation of Monthly average TEC obtained from GPS

Figure (4) shows the diurnal variation of average TEC obtained from IRI- model of every month. It also shows the typical diurnal variation of TEC with pre- dawn minimum with gradual increment, peak value at noon and gradual decrement in afternoon to minimum value after sunset. The peak value of TEC has been observed 0800 UT to 1000 UT (01:45 to $04: 45 \mathrm{LT})$ similar to the plot for GPS TEC this similar result was mentioned by Akala $e t$ al [13]. 


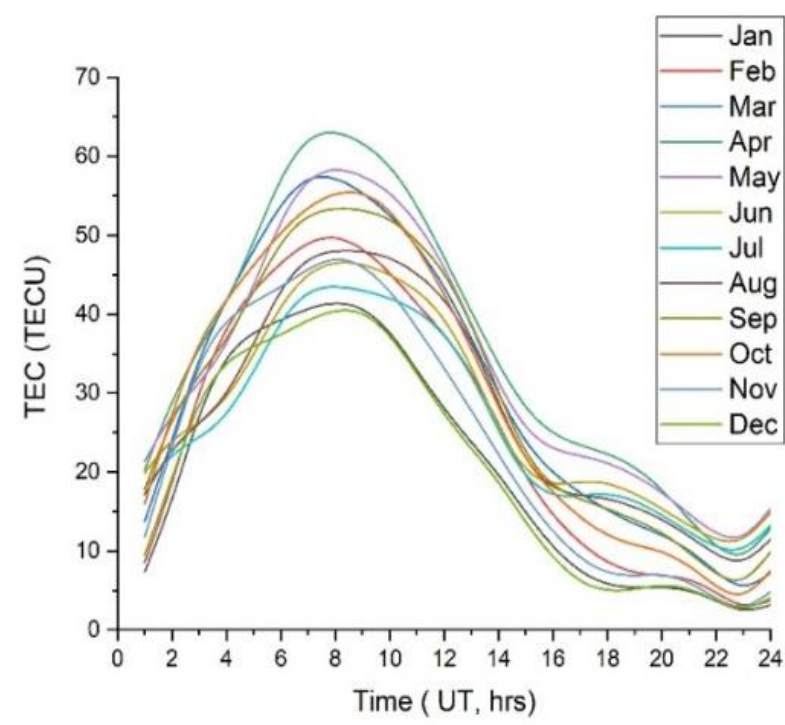

Fig. 4: Diurnal Variation of Monthly average TEC obtained from IRI- 2016

Figure (5) shows the monthly mean variations of GPS- TEC and TEC obtained from IRI- model. The highest value of TEC obtained from GPS is in month of March and TEC obtained from IRI- 2016 is in April. IRI- TEC overestimates the value of TEC in all months except in March where it underestimates the value of TEC. The overestimation can also be explained by the local climate such as monsoon in Nepal during which the value of TEC is low. From June to Mid- September, the monsoon occurs in Nepal which affects the TEC. Similarly, other local atmospheric parameters can also effect on the varations of GPS TEC.

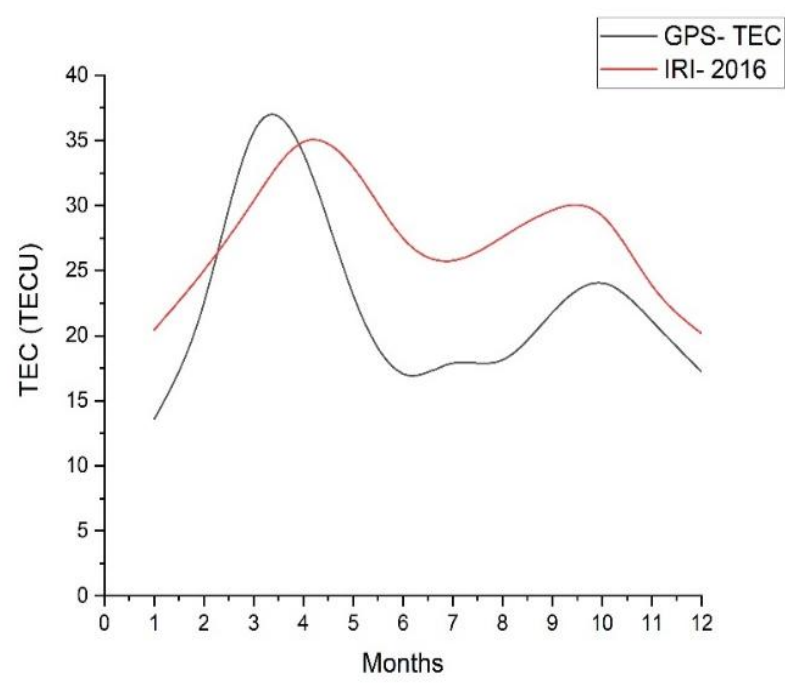

Fig. 5: Monthly mean variation of GPS- TEC and TEC obtained from IRI- model.

\subsection{Seasonal Variation}

Vertical TEC obtained from GPS and TEC obtained from IRI- model has been compared for seasonal variations. To examine such variations, GPS- TEC and TEC from IRI- 2016 model have been grouped into four local seasons i.e. Spring (March, April and May), Summer (June, July and August), Autumn (September, October and November) and Winter (December, January and February). The highest value of GPS- TEC has been found in spring and lowest in winter whereas the highest value of TEC obtained from IRI- model has been found in summer and lowest in winter. There has been found difference in the value of TEC especially during daytime noon which might be due to the difference of slab thickness in the ionosphere between the IRI model and the GPS data [5]. The maximum difference between the value of IRI TEC and GPSTEC has been found to be around 15 TECU whereas the minimum value is almost around 1 TECU. Seasonal variation of TEC is also dependent on the variation of solar flux where value of solar flux is higher in Spring and Summer. Similarly, in spring, there is a greater flow of meridional wind from equator to poles resulting in a high ionization crest value [20]. It is why there is an under estimation of TEC by IRI model compared to measured value. In winter, the ionospheric parameters are almost constant which explains less variation of GPS- TEC and IRI- TEC. The station of our study is on EIA (equatorial ionospheric anomaly) region, so there is considerable amount of effect of $\mathrm{E}^{*} \mathrm{~B}$ drift on GPS-TEC. Moreover, tropospheric delay also can affect the variation of TEC.

Figure (6) shows the comparison of variability of TEC obtained from GPS and IRI- model in spring. The highest value of GPS- TEC and TEC from IRImodel in spring has been found around 0800 UT and $1000 \mathrm{UT}$. IRI model underestimates the values of GPS- TEC in March and April while IRI- model overestimates GPS- TEC in May.

Figure (7) depicts the comparison of variability of TEC obtained from GPS and IRI in summer. The highest value of GPS- TEC and TEC obtained from IRI has been found to be around 0800 UT to 1000 UT. IRI seems to overestimate the value of TEC than GPS- TEC in June, July and August.

Figure (8) shows the comparison of variability of TEC obtained from GPS and IRI in autumn. The highest value of GPS- TEC and TEC obtained from IRI has been found around 0800 UT to 1100 UT and $0800 \mathrm{UT}$ to $0900 \mathrm{UT}$ respectively. IRI 
overestimates the value of TEC than GPS- TEC in September. It also overestimates the TEC in most of the time other than the peak value in October and November.

Similarly, Figure (9) depicts the comparison of variability of TEC obtained from GPS and IRI2016 in winter. The highest value of GPS- TEC and TEC obtained from IRI has been found around 0800 UT to 1000 UT and around 0800 UT respectively. IRI overestimates the value of TEC than GPS- TEC in December and January. It underestimates the value of TEC in February than GPS- TEC.

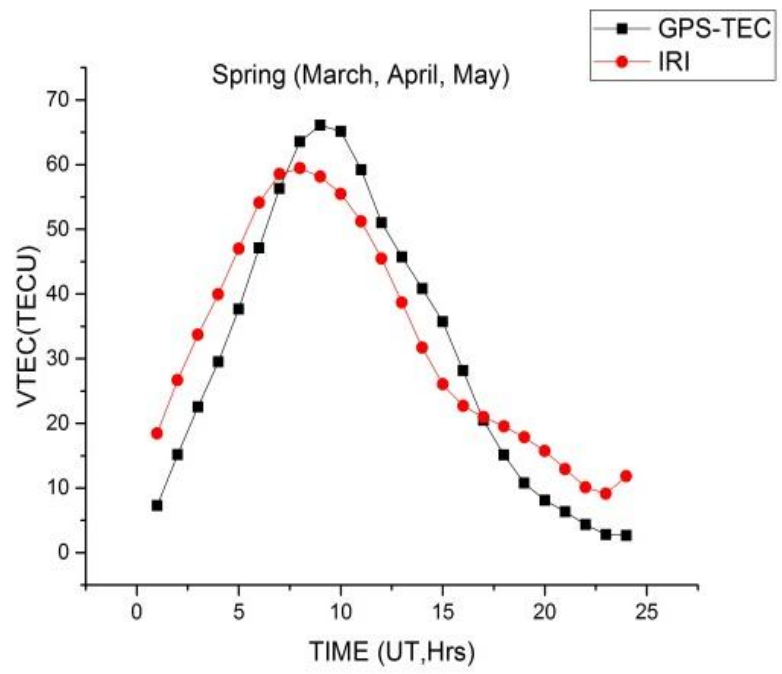

Fig. 6: Comparison of variability of GPS- TEC and IRITEC in Spring.

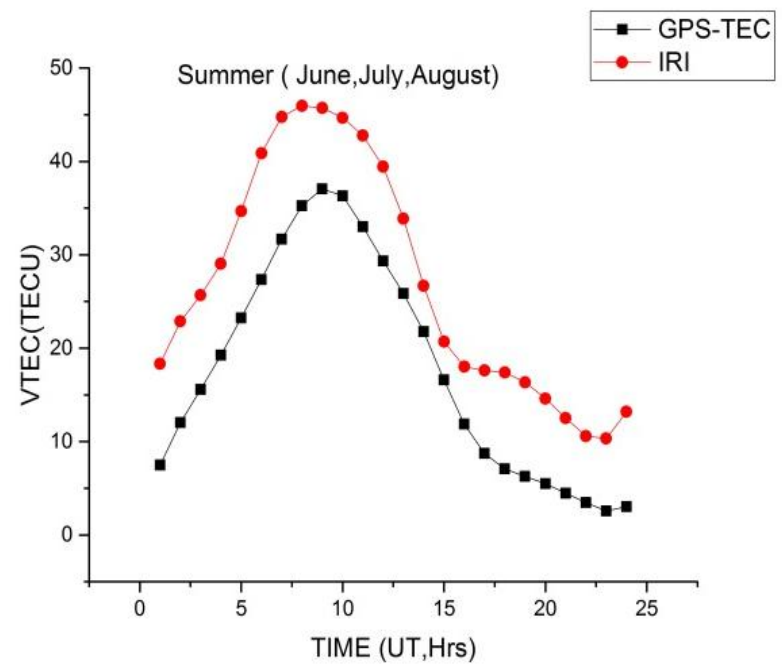

Fig. 7: Comparison of variability of GPS- TEC and IRITEC in summer

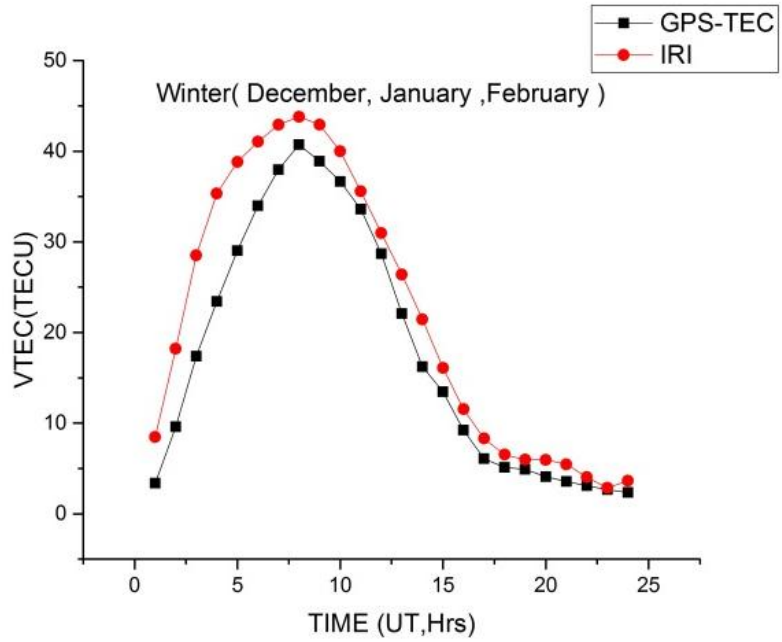

Fig. 8: Comparison of variability of GPS- TEC and IRITEC in autumn

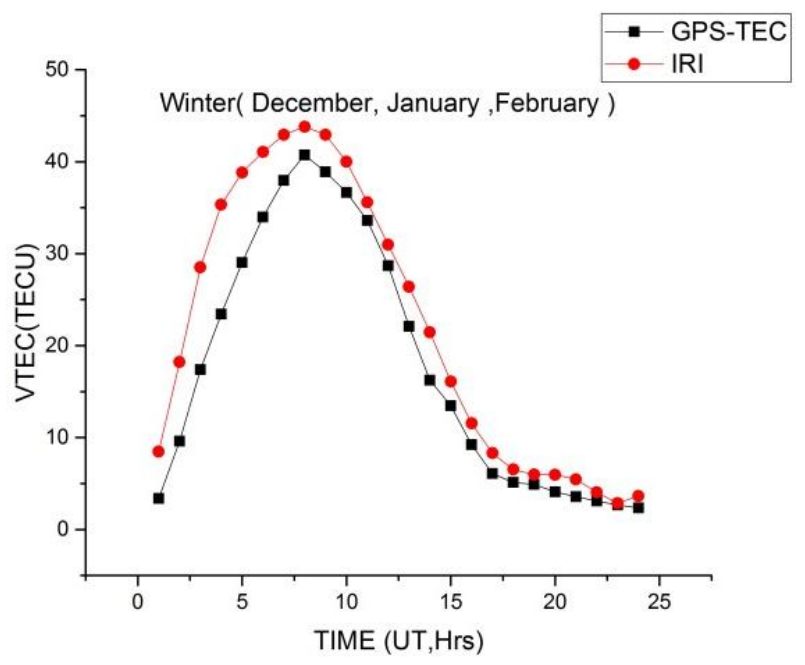

Fig. 9: Comparison of variability of GPS- TEC and IRI-TEC in winter

In Figure (10) higher values of TEC are predicated by IRI in spring season, while the lower values are in winter. From Figure (11), the values of TEC are higher in Spring, while the lowest values are in summer in before 1000UT (0345LT) and then low values are in winter thereafter. The highest value of GPS- TEC in spring is explained by the flow of matrimonial wind from equator to pole- wards creating a high ionization crest value in equatorial anomaly region [20]. The station of our study being at equatorial anomaly region, $\mathrm{E}^{*} \mathrm{~B}$ drift has a significant effect on the value of GPS- TEC. Season of autumn is found to be almost similar values in both cases. 


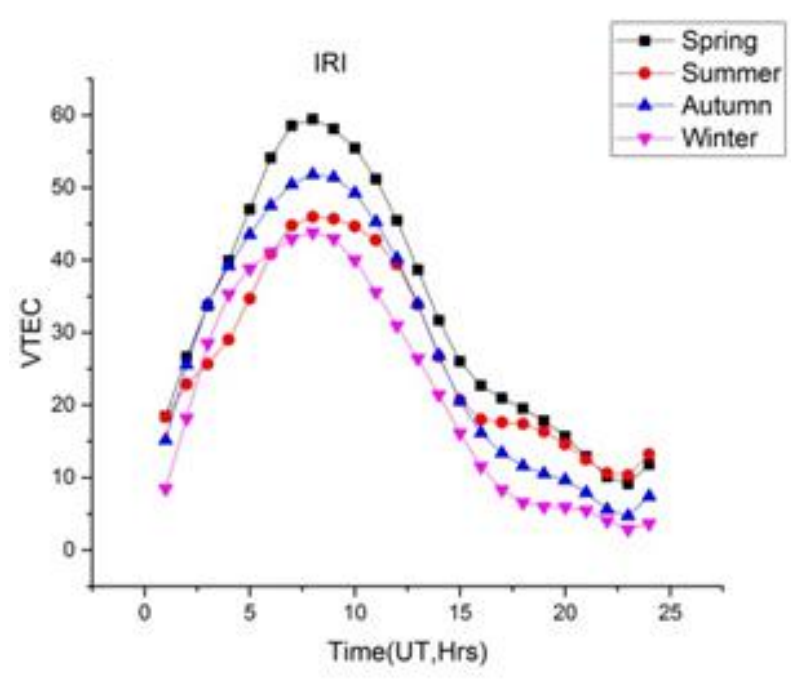

Fig. 10: Seasonal comparison of IRI TEC

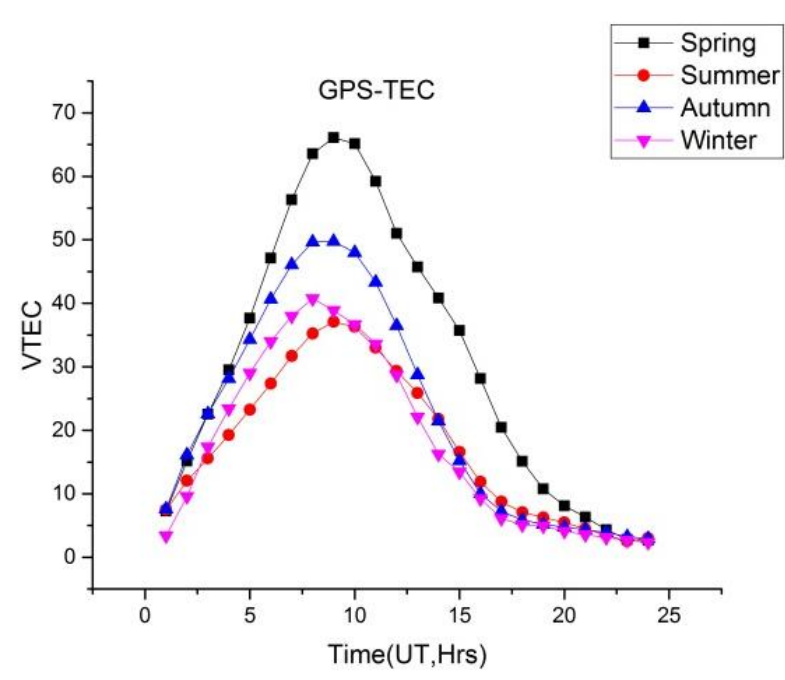

Fig. 11: Seasonal comparison of GPS-TEC

\section{CONCLUSION}

TEC data from GPS receivers over Bardiya, Nepal (latitude $=29.17^{\circ} \mathrm{N}$ and longitude $=80.62^{\circ} \mathrm{E}$ have been examined and compared with IRI modeled TEC. The value of GPS TEC increases from 0100 UT (0645 LT) and maximizes around 0800 UT to 1100 UT (0145 LT to 0445 LT). Then TEC decreases at the evening time and becomes minimum during night time which is similar for IRI model. IRI is found to overestimate the value of TEC for the most of the month during early morning hours and, some of the month during noon time. The pattern for day to day variability has been found similar with both of the values of TEC. Monthly variation plots show that IRI model TEC value is the highest in April, whereas the highest value of GPS- TEC has been found in March. Similarly, IRI model show the highest value of TEC in spring that significantly matches with GPSTEC. In case of lowest value, IRI predicted in winter where GPS- TEC showed in summer up to 1000UT (0345LT) and then in winter thereafter due to which there have been over- estimation in summer and few under estimation in winter. The maximum difference between the value of IRI modeled TEC and GPS- TEC has been found to be around 15 TECU whereas the minimum value is almost around 1 TECU. The correlation between IRI- 2016 modeled TEC and GPS- TEC has been found positive (0.578) showing good matching on variations of GPS TEC and IRI-model results.

\section{ACKNOWLEDGEMENT}

B. D. Ghimire would like to thank University Grants Commission (UGC) for PhD fellowship also authors thanks UNAVCO for providing the data of all stations and days. Authors would also like to thank OmniWeb for IRI- 2016 model data.

\section{REFERENCES}

[1] Tariku, Y. A. Patterns of GPS-TEC variation over low-latitude regions ( African sector) during the deep solar minimum ( 2008 to 2009 ) and solar maximum ( 2012 to 2013 ) phases -2. Earth Planets, (67), 1-10 (2015).

[2] Alcay, S., Oztan, G., \& Selvi, H. Z. Comparison of IRI_PLAS and IRI_2012 model predictions with GPS-TEC measurements in different latitude regions. Annals of Geophysics, 60(5), 0549 (2017).

[3] Adewale, A. O., Oyeyemi, E. O., Adeniyi, J. O., Adeloye, A. B., \& Oladipo, O. A. Comparison of total electron content predicted using the IRI2007 model with GPS observations over Lagos, Nigeria. IJRSP 40(1) (2011)

[4] Liu, G., Huang, W., Shen, H., \& Gong, J. Vertical TEC variations and model during low solar activity at a low latitude station, Xiamen. Advances in space research, 49(3), 530538 (2012).

[5] Kenpankho, P., Watthanasangmechai, K., Supnithi, P., Tsugawa, T., \& Maruyama, T. Comparison of GPS TEC measurements with IRI TEC prediction at the equatorial latitude station, Chumphon, Thailand. Earth, planets and space, 63(4), 365-370 (2011).

[6] Tsai, H.F., Liu, J.-Y., Tsai, W.-H., Liu, C.-H., Tseng, C.-L., Wu, C.-C. Seasonal variations of the ionospheric total electron content in Asian equatorial anomaly regions. J. Geophys. 106, 
30363-30369, (2001).

[7] Wu, C.C., Fry, C.D., Liu, J.Y., Liou, K., Tseng, C.L. Annual TEC variation in the equatorial anomaly region during the solar minimum: September1996- August 1997. Journal of atmospheric and solar terrestrial physics 66, 199-207 (2004).

[8] Kumar, S., Tan, E. L., Razul, S. G., See, C. M. S., \& Siingh, D. Validation of the IRI-2012 model with GPS-based ground observation over a lowlatitude Singapore station. Earth, Planets and Space, 66(1), 17 (2014).

[9] Bagiya, M. S., Joshi, H. P., Iyer, K. N., Aggarwal, M., Ravindran, S., \& Pathan, B. M. TEC variations during low solar activity period (20052007) near the equatorial ionospheric anomaly crest region in India. In Annales Geophysicae (27)3, 1047-1057(2009) .

[10] Kumar, S., Tan, E. L., \& Murti, D. S. Impacts of solar activity on performance of the IRI-2012 model predictions from low to midlatitudes. Earth, Planets and Space, 67(1), 42 (2015).

[11] VanVelthoven P. Medium scale irregularities in the ionospheric electron content, Ph. D. Thesis, Mathematical Geodesy and Positioning Faculty of Civil Engineering and Geosciences Delft University of Technology Thijsseweg 11, 2629 JA Delft, The Netherlands (1990).

[12] Warnant, R. The increase of ionospheric activity as measured by GPS, Earth Planets Space, 52, 1055-1060, (2000).

[13] Akala, A.O., Somoye, E.O., Adewale, A.O., Ojutalayo, E.W., Karia, S.P., Idolor, R.O., Okoh, D., Doherty, P.H. Comparison of GPS_TEC observations over Addis Ababa with IRI_2012 model predictions during 2010-2013. Advances in Space Research, 56, 1686-1698 (2015).
[14] Abdu,M.A.,Brum,C.G.M., Batista, I.S., Sobral, J.H.A., de Paula, E.R. and Souza, J.R. Solar flux effects on equatorial ionization anomaly and total electron content over Brazil: observational results versus IRI representations. Advances in Space Research, 42, 617-625 (2008).

[15] Bilitza, D., Altadill, D., Truhlik, V., Shubin, V., Galkin, I., Reinisch, B., \& Huang, X. International Reference Ionosphere 2016: From ionospheric climate to real-time weather predictions. Space Weather, 15(2), 418-429 (2017).

[16] Hajra, R., Chakraborty, S. K., Tsurutani, B. T., DasGupta, A., Echer, E., Brum, C. G. \& Sobral, J. H. A. An empirical model of ionospheric total electron content (TEC) near the crest of the equatorial ionization anomaly (EIA). Journal of Space Weather and Space Climate, 6, A29 (2016).

[17] Olwendo, O. J., Baki, P., Cilliers, P. J., Mito, C., $\&$ Doherty. Comparison of GPS TEC variations with IRI-2007 TEC prediction at equatorial latitudes during a low solar activity (2009-2011) phase over the Kenyan region. Advances in Space Research, 52(10),1770-1779, (2013).

[18] Bilitza, D., Bodo, L. M. and Fuller-rowell, T. The international reference ionosphere today and in the future.Geodesy,85,909-920 (2011)

[19] Rama Rao, P. V. S., Niranjan, K., Prasad, D. S. V. V. D., Gopi Krishna, S., \& Uma, G. On the validity of the ionospheric pierce point (IPP) altitude of $350 \mathrm{~km}$ in the Indian equatorial and low-latitude sector. Annales Geophysicae, 24(8), 2159-2168 . (2006).

[20] Chakraborty, M., Kumar, S., De, B. K., \& Guha, A.. Latitudinal characteristics of GPS derived ionospheric TEC : a comparative study with IRI 2012 model. Annals of geophysics, 57(5), A0539 A0544 (2014). 